\title{
Los vínculos entre el jefe del Estado y los ministros análisis protocolario de actos oficiales celebrados durante el régimen franquista
}

\author{
The links between the head of the state and the ministers \\ Protocolary analysis of official acts celebrated during the Franco \\ regime
}

\author{
Elizabet Castillero-Ostio ${ }^{1}$ y Antonio Castillo-Esparcia ${ }^{2}$ \\ Universidad de Málaga \\ ecastillero@uma.es; acastilloe@uma.es
}

Recepción: 14/12/18 Revisión: 20/12/18 Aceptación: 20/12/18 Publicación: 28/12/18

\begin{abstract}
Resumen
En el presente artículo se realiza un recorrido por las carteras ministeriales de las distintas formaciones gubernamentales sucedidas durante el régimen franquista a través del análisis de la presencia y ubicación de los ministros en los actos celebrados en el Día de la Hispanidad-Raza (12 de octubre) y en el de San José Artesano (1 de mayo). Hemos acudido a la argumentación de diferentes autores tratando de conocer las carreras políticas de cada uno de los componentes de los distintos gobiernos franquistas que más aparecen en los actos analizados o lo hacen en posiciones privilegiadas, además de detallar los posibles vínculos que los unían al Jefe del Estado. Todo ello, para tratar de determinar si existe algún indicio que indique la puesta en práctica de un criterio subjetivo a la hora de invitar y ordenar a las autoridades en los actos que responda a los intereses del Régimen, en concreto a la cabeza visible de este, su Jefe, permitiéndonos este hecho reflejar el estado de los vínculos que unen a la institución con sus públicos en cada momento.
\end{abstract}

Palabras clave: Franquismo, ministros, relaciones, actos oficiales, protocolo

\footnotetext{
${ }^{1}$ Elizabet Castillero-Ostio: Profesora e investigadora del Departamento de Comunicación Audiovisual y Publicidad de la Universidad de Málaga, UMA, España.

2 Antonio Castillo-Esparcia: Catedrático del Departamento de Comunicación Audiovisual y Publicidad de la Universidad de Málaga, UMA, España
} 


\begin{abstract}
In the present article we will provide an overview of the different ministerial portfolios in the government during the Franco regime by analyzing the presence and location of the ministers in the acts that took place during the Hispanic Heritage and Race Day (12th, October) and St. Joseph Artisan's Day (1st, May). We have looked through the argumentations made by different writers in order to know more about their political careers of each one of the members who seemed to appear more often in those acts, or appearing from privileged positions, along the different governments during Franco times, as well as detailing the possible links between the Head of State and them. The purpose is to determine the existence of any evidence which indicates an actual subjective criteria at the time of inviting and positioning the different members of authorities in the above mentioned acts responding to the interests of the regime, particularly those of the Head of State. Thus, it would allow us to reflect the nature of the links between the institution and their audiences in any given time.
\end{abstract}

Keywords: Franco regime, ministers, relationships, official acts, protocol

\title{
Sumario
}

1. Introducción

2. Metodología de la investigación y objetivos a alcanzar

3. Resultados de la investigación

3.1. Resultados del análisis de los actos oficiales del Día de la Hispanidad-Raza

3.2. Resultados del análisis de los actos oficiales del Día de San José Artesano

4. Conclusiones

5. Referencias

\section{INTRODUCCIÓN}

La denominada comunicación no verbal, como uno de los componentes del proceso de la comunicación, debe ser tratada con la misma, e incluso con más importancia que la verbal, ya que aunque muchas veces no somos totalmente conscientes de su presencia, tiene una gran transcendencia en la descodificación del mensaje que nos están transmitiendo.

Valiéndonos del mensaje que nos puede proporcionar esta modalidad de comunicación, se pretende realizar un análisis de la presencia y ubicación de los ministros que forman parte del régimen franquista en los actos analizados. La ordenación y emplazamiento de este grupo se presenta en este caso como un termómetro que refleja el estado de los vínculos o lazos entre la institución, en este caso el Estado representado por Francisco Franco, y uno de sus públicos internos (cada ministro) en cada momento a lo largo de los años de supervivencia del Régimen. 


\section{METODOLOGÍA DE LA INVESTIGACIÓN Y OBJETIVOS A ALCANZAR}

Esta investigación es un estudio de tipo histórico, que se ha valido de la consulta de fuentes documentales y el análisis de contenido mixto como técnicas metodológicas.

Se ha analizado tanto la información proporcionada por dos publicaciones periódicas sobre la celebración de unos actos oficiales, como los recursos gráficos (fotografías) que además proporcionaban aclaraciones expuestas en los pies de página.

Han sido estudiadas las noticias extraídas de dos periódicos considerados como referentes en la época estudiada, el franquismo (1939-1975), ABC y La Vanguardia Española. Los actos oficiales examinados son aquellos que se celebraron en el Día de la Hispanidad (12 de octubre), también conocido durante el primer periodo franquista como "Día de la Raza" y el Primero de Mayo o San José Artesano. Concretamente los actos localizados, y por tanto analizados, son en total 120: 92 actos celebrados en el Día de la Hispanidad-Raza y 28 en el Día de San José Artesano.

Tras la localización de estas noticias, se han confeccionado unas fichas que han tenido en cuenta las siguientes variables de análisis:

1. Lugar y fecha de la celebración del acto

2. Presencia/Ausencia de los ministros

3. Ministros que presiden el acto
4. Ministros concurrentes en la presidencia

5. Ubicación de los ministros en la presidencia

6. Asistencia del resto de ministros al acto

Los objetivos que se quieren alcanzar con este análisis son:

1. Conocer la asistencia y el emplazamiento de uno de los públicos internos de la institución, los ministros.

2. Descubrir los vínculos existentes entre el Estado, concretamente el Jefe de este, y este público específico para poder determinar si se sigue un criterio subjetivo a la hora de invitar y/o colocar a los ministros en los actos, en lugar de acatar la legislación vigente en materia de protocolo ${ }^{3}$.

\footnotetext{
${ }^{3}$ Legislación en materia de protocolo vigente durante el régimen franquista:

Decreto 1483/68 de 27 de junio de 1968 sobre ACTOS OFICIALES. Reglamento de precedencias y ordenación de autoridades y corporaciones. Publicado en el BOE, núm. 167, de 12 de julio de 1968.

Decreto 2622/1970 de 12 de septiembre de 1970, por el que se da nueva redacción a los artículos 14 y 16 del Reglamento de Precedencias y Ordenación de Autoridades y Corporaciones. Publicado en el BOE núm. 229,24 de septiembre de 1970.

Otra legislación sobre precedencias y ordenación de autoridades que, aunque no son promulgadas durante la época, tienen vigencia durante un periodo del régimen franquista, el anterior a 1968, por no haber sido derogada expresamente. Hasta esta fecha conviven en España una serie de disposiciones legales en materia de
} 
3. Demostrar que el protocolo es una técnica de gestión de públicos que se usa en las relaciones públicas institucionales, especialmente del Estado.

\section{RESULTADOS DE LA INVESTIGACIÓN}

\subsection{Resultados del análisis de los actos oficiales del Día de la Hispanidad-Raza}

\begin{tabular}{cccc} 
MINISTERIO & $\begin{array}{c}\text { No DE VECES QUE } \\
\text { ACUDEN A LOS ACTOS } \\
\text { CELEBRADOS }\end{array}$ & $\begin{array}{c}\text { No DE VECES QUE } \\
\text { CONCURREN EN LA } \\
\text { PRESIDENCIA }\end{array}$ & $\begin{array}{c}\text { No DE VECES QUE } \\
\text { PRESIDEN LOS ACTOS } \\
\text { CELEBRADOS }\end{array}$ \\
\hline Presidente del Gobierno & $\mathbf{2}$ & $\mathbf{1}$ & $\mathbf{0}$ \\
\hline $\begin{array}{c}\text { Carlos Arias Navarro } \\
\text { Vicepresidente del } \\
\text { Gobierno }\end{array}$ & 2 & 1 & $\mathbf{2}$ \\
\hline $\begin{array}{c}\text { Agustín Muñoz Grandes } \\
\text { Subsecretario de la } \\
\text { presidencia }\end{array}$ & 4 & 1 & 2 \\
\hline Luis Carrero Blanco & $\mathbf{2}$ & $\mathbf{1}$ & $\mathbf{0}$ \\
\hline Gobernación & 2 & 1 & 0 \\
\hline Ramón Serrano Suñer & 30 & $\mathbf{9}$ & $\mathbf{6}$ \\
\hline Blas Pérez González & 1 & 0 & 1 \\
\hline Camilo Alonso Vega & 13 & 6 & 1 \\
\hline Tomás Garicano Goñi & 11 & 2 & 4 \\
\hline Carlos Arias Navarro & 3 & 0 & 0 \\
\hline
\end{tabular}

Cuadro 1: Ministros que más asisten a los actos del Día de la Hispanidad-Raza, los presiden o forman parte de sus presidencias.

Fuente: Elaboración propia.

precedencias en actos públicos que incluso pueden llegar a ser contradictorias. Este es entre otros, un motivo por el que se presenta necesaria la redacción al decreto de 1968:

- Real Orden Circular de 19 de enero de 1926 que pretende la ordenación de las Autoridades y Corporaciones en las recepciones y besamanos que se celebren donde no residan Sus Majestades, en la Gaceta de Madrid núm. 20, p. 324.

- Decreto de 31 de marzo de 1943 sobre la consideración que corresponde al Presidente de las Cortes Españolas, en el BOE de 4 de abril de 1943, p. 2960.

- Orden de 2 de octubre de 1951 sobre el orden de prelación de los diversos Departamentos ministeriales a actos oficiales, en el BOE de 4 de octubre de 1951, núm. 277, p. 4516. 


\begin{tabular}{|c|c|c|c|}
\hline MINISTERIO & $\begin{array}{c}\text { № DE VECES QUE } \\
\text { ACUDEN A LOS } \\
\text { ACTOS CELEBRADOS }\end{array}$ & $\begin{array}{l}\text { № DE VECES QUE } \\
\text { CONCURREN EN } \\
\text { LA PRESIDENCIA }\end{array}$ & $\begin{array}{c}\text { № DE VECES QUE } \\
\text { PRESIDEN LOS } \\
\text { ACTOS CELEBRADOS }\end{array}$ \\
\hline Gobernación & 30 & 9 & 6 \\
\hline José García Hernández & 1 & 0 & 0 \\
\hline Asuntos Exteriores & 43 & 12 & 22 \\
\hline Juan Beigbeder y Atienza & 2 & 0 & 1 \\
\hline Ramón Serrano Suñer & 1 & 1 & 0 \\
\hline Francisco Gómez-Jordana y Sousa & 3 & 0 & 3 \\
\hline José Félix de Lequerica y Esquiza & 1 & 0 & 1 \\
\hline Alberto Martín Artajo & 22 & 10 & 4 \\
\hline Fernando Mạ Castiella y Maíz & 7 & 0 & 7 \\
\hline Gregorio López-Bravo y Castro & 2 & 0 & 2 \\
\hline Laureano López Rodó & 2 & 0 & 2 \\
\hline Pedro Cortina Mauri & 3 & 2 & 1 \\
\hline Ejército & 16 & 4 & 1 \\
\hline Carlos Asensio Cabanillas & 1 & 0 & 0 \\
\hline Fidel Dávila Arrondo & 5 & 1 & 0 \\
\hline Agustín Muñoz Grandes & 1 & 1 & 0 \\
\hline Antonio Barroso y Sánchez Guerra & 1 & 0 & 1 \\
\hline Pablo Martín Alonso & 1 & 1 & 0 \\
\hline Camilo Menéndez Tolosa & 3 & 0 & 0 \\
\hline Juan Castañón de Mena & 3 & 1 & 0 \\
\hline Francisco Coloma Gallegos & 1 & 0 & 0 \\
\hline Marina & 18 & 7 & 2 \\
\hline Salvador Moreno Fernández & 6 & 3 & 0 \\
\hline Francisco Regalado Rodríguez & 4 & 1 & 0 \\
\hline Felipe Abárzuza Oliva & 2 & 0 & 2 \\
\hline Pedro Nieto Antúnez & 3 & 2 & 0 \\
\hline Adolfo Baturone & 2 & 1 & 0 \\
\hline Gabriel Pita de Veiga & 1 & 0 & 0 \\
\hline Aire & 15 & 6 & 0 \\
\hline Juan Vigón Suerodíaz & 2 & 1 & 0 \\
\hline Eduardo González Gallarza & 4 & 2 & 0 \\
\hline José Rodríguez y Díaz de Lecea & 1 & 1 & 0 \\
\hline José Lacalle Larraga & 3 & 1 & 0 \\
\hline Julio Salvador Díez-Benjumea & 4 & 1 & 0 \\
\hline Mariano Cuadra Medina & 1 & 0 & 0 \\
\hline Educación Nacional & 31 & 18 & 5 \\
\hline José Ibáñez Martín & 19 & 11 & 4 \\
\hline Joaquín Ruiz-Giménez Cortés & 9 & 5 & 0 \\
\hline Jesús Rubio García-Mina & 1 & 1 & 0 \\
\hline Julio Rodríguez Martínez & 2 & 1 & 1 \\
\hline Obras Públicas & 13 & 4 & 0 \\
\hline Alfonso Peña Boeuf & 2 & 1 & 0 \\
\hline José María Fernández Ladreda & 5 & 1 & 0 \\
\hline $\begin{array}{l}\text { Fernando Suárez de Tangil y Angulo, } \\
\text { Conde de Vallellano }\end{array}$ & 5 & 2 & 0 \\
\hline Jorge Vigón Suerodíaz & 1 & 0 & 0 \\
\hline Industria y Comercio & 7 & 2 & 0 \\
\hline Demetrio Carceller & 2 & 1 & 0 \\
\hline
\end{tabular}




\begin{tabular}{|c|c|c|c|}
\hline MINISTERIO & $\begin{array}{c}\text { № DE VECES QUE } \\
\text { ACUDEN A LOS } \\
\text { ACTOS CELEBRADOS }\end{array}$ & $\begin{array}{l}\text { № DE VECES QUE } \\
\text { CONCURREN EN } \\
\text { LA PRESIDENCIA }\end{array}$ & $\begin{array}{c}\text { № DE VECES QUE } \\
\text { PRESIDEN LOS ACTOS } \\
\text { CELEBRADOS }\end{array}$ \\
\hline Industria y Comercio & 7 & 2 & 0 \\
\hline Juan Antonio Suanzes Fernández & 5 & 1 & 0 \\
\hline Industria & 5 & 2 & 0 \\
\hline Joaquín Planell Riera & 5 & 2 & 0 \\
\hline Comercio & 4 & 0 & 0 \\
\hline Manuel Arburúa de la Miyar & 3 & 0 & 0 \\
\hline Alberto Ullastres Calvo & 1 & 0 & 0 \\
\hline Agricultura & 9 & 3 & 0 \\
\hline Joaquín Benjumea Burín & 1 & 0 & 0 \\
\hline Miguel Primo de Rivera & 3 & 2 & 0 \\
\hline Carlos Rein Segura & 1 & 0 & 0 \\
\hline Rafael Cavestany & 3 & 1 & 0 \\
\hline Adolfo Díaz- Ambrona Moreno & 1 & 0 & 0 \\
\hline Vivienda & 1 & 0 & 0 \\
\hline José Utrera Molina & 1 & 0 & 0 \\
\hline Hacienda & 7 & 3 & 0 \\
\hline Joaquín Benjumea Burín & 3 & 3 & 0 \\
\hline Francisco Gómez del Llano & 2 & 0 & 0 \\
\hline Juan José Espinosa San Martín & 2 & 0 & 0 \\
\hline Trabajo & 6 & 3 & 0 \\
\hline José Antonio Girón de Velasco & 3 & 2 & 0 \\
\hline Jesús Romeo Gorría & 3 & 1 & 0 \\
\hline Justicia & 12 & 5 & 0 \\
\hline Esteban Bilbao y Eguía & 1 & 1 & 0 \\
\hline Eduardo Aunós Pérez & 1 & 1 & 0 \\
\hline Raimundo Fernández Cuesta & 4 & 1 & 0 \\
\hline Antonio Iturmendi Bañales & 2 & 1 & 0 \\
\hline Antonio María Oriol y Urquijo & 3 & 1 & 0 \\
\hline Francisco Ruiz-Jarabo y Baquero & 1 & 0 & 0 \\
\hline Información y Turismo & 5 & 2 & 1 \\
\hline Gabriel Arias Salgado & 1 & 1 & 0 \\
\hline Manuel Fraga Iribarne & 1 & 0 & 0 \\
\hline Alfredo Sánchez Bella & 3 & 1 & 1 \\
\hline Secretario General Del Movimiento & 9 & 3 & 0 \\
\hline Agustín Muñoz Grandes & 1 & 0 & 0 \\
\hline José Luis de Arrese y Magra & 2 & 1 & 0 \\
\hline Raimundo Fernández Cuesta & 3 & 1 & 0 \\
\hline José Solís Ruiz & 2 & 1 & 0 \\
\hline Torcuato Fernández Miranda & 1 & 0 & 0 \\
\hline Relaciones Sindicales & 2 & 0 & 0 \\
\hline Enrique García Ramal y Ceballo & 1 & 0 & 0 \\
\hline Alejandro Fernández Sordo & 1 & 0 & 0 \\
\hline Ministros sin cartera & 5 & 4 & 0 \\
\hline Pedro Gamero del Castillo & 1 & 1 & 0 \\
\hline Pedro Gual Villalbí & 3 & 3 & 0 \\
\hline Rafael Sánchez Mazas & 1 & 0 & 0 \\
\hline
\end{tabular}




\section{NOMBRE Y CARGOS}

Carlos Arias Navarro

Como Presidente del Gobierno y Ministro de la Gobernación

\section{Agustín Muñoz Grandes}

Como Vicepresidente del Gobierno y Ministro del Ejército y Secretario General del Movimiento

Ramón Serrano Suñer

Como Ministro de la Gobernación y Asuntos Exteriores

\section{№ DE VECES QUE ACUDE A LOS ACTOS CELEBRADOS}

3

2

\section{№ DE VECES QUE CONCURRE EN LA PRESIDENCIA}

№ DE VECES QUE

PRESIDE LOS ACTOS

CELEBRADOS
1

2

1
0

2

1

Cuadro 2: Autoridades con varios cargos ministeriales que más asisten, presiden o concurren en las presidencias de los actos del Día de la Hispanidad-Raza.

Fuente: Elaboración propia.

\begin{tabular}{|c|c|c|c|}
\hline $\begin{array}{c}\text { SUBSECRETARIOS Y } \\
\text { OTROS CARGOS DE LOS } \\
\text { DISTINTOS MINISTERIOS }\end{array}$ & $\begin{array}{l}\text { № DE VECES QUE } \\
\text { ACUDEN A LOS ACTOS } \\
\text { CELEBRADOS }\end{array}$ & $\begin{array}{l}\text { NNo DE VECES QUE } \\
\text { CONCURREN EN LA } \\
\text { PRESIDENCIA }\end{array}$ & $\begin{array}{l}\text { № DE VECES QUE } \\
\text { PRESIDEN LOS ACTOS } \\
\text { CELEBRADOS }\end{array}$ \\
\hline Subsecretario del Aire & 5 & 2 & 0 \\
\hline Subsecretario de Justicia & 2 & 0 & 0 \\
\hline $\begin{array}{l}\text { Subsecretario de la } \\
\text { Marina }\end{array}$ & 2 & 0 & 0 \\
\hline $\begin{array}{c}\text { Subsecretario de } \\
\text { Educación Nacional }\end{array}$ & 8 & 0 & 0 \\
\hline $\begin{array}{c}\text { Subsecretario de Asuntos } \\
\text { Exteriores }\end{array}$ & 11 & 1 & 4 \\
\hline $\begin{array}{c}\text { Subsecretario de } \\
\text { Gobernación }\end{array}$ & 4 & 0 & 1 \\
\hline $\begin{array}{c}\text { Subsecretario de } \\
\text { Agricultura }\end{array}$ & 4 & 0 & 0 \\
\hline $\begin{array}{l}\text { Subsecretario de } \\
\text { Industria }\end{array}$ & 2 & 1 & 0 \\
\hline Subsecretario del Ejército & 3 & 0 & 0 \\
\hline $\begin{array}{c}\text { Subsecretario de } \\
\text { Hacienda }\end{array}$ & 2 & 0 & 0 \\
\hline $\begin{array}{c}\text { Subsecretario de } \\
\text { Información y Prensa }\end{array}$ & 1 & 0 & 0 \\
\hline Subsecretario de Trabajo & 2 & 0 & 0 \\
\hline $\begin{array}{l}\text { Vicesecretario de Gral. } \\
\text { Del Movimiento }\end{array}$ & 4 & 0 & 0 \\
\hline
\end{tabular}

Cuadro 3: Subsecretarios y otros cargos ministeriales que más asisten, presiden o concurren en las presidencias de los actos del Día de la Hispanidad-Raza.

Fuente: Elaboración propia. 
Entre los actos celebrados en el Día de la Hispanidad-Raza durante el régimen franquista, en siete ocasiones no se concreta la asistencia de los ministros. Pero se informa de que asiste "el gobierno en pleno", aunque eso sí, sin especificarse de qué ministerio provienen. La ubicación de estos, con asiduidad, es en la primera fila de escaños. Además, en 1950 y 1951 se informa de que asisten los subsecretarios de los distintos departamentos; los cuáles tampoco se concretan.

El ministro que más veces acude a los actos celebrados en el Día de la HispanidadRaza es el ministro de Asuntos Exteriores con 43 apariciones. En 22 ocasiones lo hace presidiendo el acto y en 12 concurre en la presidencia. El resto de las veces que acude no está presente en la mesa presidencial. Se tiene constancia, además, que en 4 ocasiones el subsecretario de este Ministerio ha ocupado la presidencia con el fin de representar al ministro de dicha cartera.

Hay que tener en cuenta que muchos de los actos celebrados en esta fecha son sesiones académicas o sesiones extraordinarias del Instituto de Cultura Hispánica, el cual nace el 31 de diciembre de 1945 como sucesor del Consejo de la Hispanidad (fundado en noviembre de 1940). Este organismo antecesor nace con rango de asesor dependiente del Ministerio de Asuntos Exteriores y con una clara inclinación política. Es el encargado de la política exterior en el continente americano, cuya misión primordial es extender por América Latina los ideales del Régimen y neutralizar las instituciones republicanas restablecidas en el exilio. Esta institución, además contaba con una sección cultural. Pasados los años y dadas las dificultades con las que se encontraba la política exterior, se consideró que el instrumento para recuperar la capacidad de influencia y el prestigio español en América tenía que ser la cultura. En este caso, una cultura con los valores de la dictadura y el sistema político imperante en España. A esta razón se debe el nacimiento del Instituto de Cultura Hispánica ${ }^{4}$.

Que este organismo esté adscrito al ministerio de Asuntos Exteriores y que la mayoría de los presidentes de este sean los titulares de este ministerio: Alberto Martín Artajo, Fernando María Castiella y Gregorio López Bravo, explican la asistencia de los ministros de Asuntos Exteriores y la concurrencia de estos en la presidencia de los diferentes actos celebrados el 12 de octubre en los que tienen relación al Instituto de Cultura Hispánica.

El ministro que más veces ha ostentado la presidencia es el ministro de Asuntos Exteriores Fernando María Castiella (en 7 ocasiones). Los actos que ha presidido son actos académicos del Instituto de Cultura Hispánica, como presidente del mismo y otros actos académicos de afirmación hispánica con sus respectivos almuerzos y Te Deum de acción de

\footnotetext{
${ }^{4}$ Información recogida en la página web Migraventura.net, la España que emigró a América. Esta web pertenece a Fundación Directa y está financiada por el Ministerio de Trabajo e Inmigración, así como apoyada por dos instituciones pertenecientes a este ministerio: la Dirección General de la Ciudadanía Española en el Exterior (DGCEE) y la Agencia Española de Cooperación Internacional para el desarrollo (AECID).
} 
gracias. Los años en los que Castiella ha presidido dichos actos están comprendidos entre 1958 y 1964; años en los que aparece como "como una figura de consenso, sin lazos comprometedores con ninguno de los grupos en lid y tan equidistante de ellos como el propio Franco" (Pardo Sanz, 1996: 235). Estos son los 7 primeros de los casi 13 años de su carrera en política nacional.

Tal y como relata Pardo Sanz (1996), en febrero de 1957, ante la crisis originada por el proyecto de Arrese de fortalecer a Falange y de "refalangistizar" al Régimen que tanta agitación provocó en las familias que lo conforman y ante la inevitable confrontación sobre todo con la Iglesia Católica, Castiella es nombrado ministro de Asuntos Exteriores. Lo que encauzó a este hecho son las reuniones que mantuvo como embajador ante la Santa Sede defendiendo los intereses del Régimen, aún más que su antecesor en esta misión, Ruiz Giménez o su antecesor en el Ministerio de Asuntos Exteriores, Martín Artajo. Actuaciones que tuvieron en cuenta tanto el Jefe del Estado como Carrero Blanco para proponerle ser titular de un departamento ministerial. Los últimos años como ministro culminaron en la crisis de 1969, en la que fue destituido; ya que sus estrategias e intereses estaban difiriendo de los marcados por el Régimen.

El segundo ministro en la lista de presidencias es el ministro de Asuntos Exteriores, Alberto Martín Artajo, antecesor a Fernando María Castiella. Preside los actos en 4 ocasiones. En algunas de estas apariciones la presencia del Ministerio de Asuntos Exteriores no se ve justificada por la naturaleza del acto. Encontramos dos ejemplos cuando comparte la presidencia con el ministro de Educación Nacional en 1945 en la bendición y colocación de la primera piedra del Colegio Mayor de San Pablo, creado por la Asociación de Propagandistas y Centro de Estudios Universitarios. Y en 1947, con la entrega simbólica de terreno para edificar en la Ciudad Universitaria de Madrid. La presidencia del acto por parte del ministro de Educación está totalmente justificada, al tratarse de la inauguración de dependencias destinadas al campo de la Educación. Pero no se justifica la presencia del Sr. Martín Artajo, aunque sí exista en el caso del acto de 1945 relación de ambos ministros, propagandistas católicos, con la asociación que crea el colegio inaugurado.

Por último, encontramos en 1955 que también Martín Artajo preside un acto en homenaje a Colón, ostentando la representación del Caudillo; representando este hecho el poder y la confianza que el Jefe del Estado deposita en él.

Las presidencias antes descritas pueden guardar relación con que es en julio de 1945 cuando se produce un aumento de poder de la Iglesia dentro del régimen franquista. Símbolo de este hecho es el reajuste importante de gobierno al destituirse a José Luis Arrese de la cartera de Secretaria General del Partido. Tal y como apunta Lazo Díaz (2008: 284) "pieza fundamental para desfastizar a España y para que Falange perdiera poder". Y el nombramiento de Alberto Martín Artajo como ministro de Asuntos Exteriores, presidente 
hasta entonces de Acción Católica de España. Así describen a este ministro Del Arco, De Miguel y Romero ${ }^{5}$ :

(...) ha sido el líder máximo del sector político conocido como la democracia cristiana franquista". Además afirman que “(...) disfrutó de una importante parcela de poder y prestó inestimables servicios a Franco en la época conocida como la del "bloqueo a España por las potencias extranjeras.

Además de ser el segundo ministro que más veces preside los actos conmemorativos del Día de la Hispanidad-Raza, también es uno de los que más veces ha estado concurriendo en la mesa presidencial (10 ocasiones) junto a Ibáñez Martín con 11 ocasiones. Además de ser el ministro que más veces ha asistido a los actos celebrados en esta fecha. Estos están conformados por actos académicos y sesiones extraordinarias del Instituto de Cultura Hispánica, así como funciones religiosas (1950), ceremonias conmemorativas al V centenario de los Reyes Católicos y sesiones académicas del Consejo Superior de Investigaciones Científicas.

En la mayoría de los actos, Martín Artajo se sienta a la derecha del Jefe del Estado, hecho que indica la importancia de esta autoridad en los actos celebrados, teniendo en cuenta las normas de protocolo y la ley de la derecha como puesto de honor. En dos ocasiones ocupa el 20 puesto a la derecha de Franco (el 5o y 40 puesto dentro de la mesa presidencial). Y en una ocasión, en 1951, en la inauguración del Instituto de Cultura Hispánica, se coloca a la izquierda del Caudillo, en el 30 puesto después del ministro de Relaciones Exteriores del Perú Sr. Gallagher.

Pero además de asistir a estos actos académicos, los ministros de Asuntos Exteriores también han asistido a exposiciones que hacen referencia al mundo hispanoamericano y funciones religiosas; ambos actos organizados por el Ministerio de Asuntos Exteriores en honor a los caídos en Hispanoamérica y a los Reyes Católicos. La presencia de los ministros pertenecientes a este departamento ministerial se ve justificada por el papel que dichas autoridades ejercen en la política exterior en Iberoamérica. Pero se puede observar, a la vez, el poder ostentado por este ministerio, y en consecuencia por los titulares de dichas carteras en ese momento para poder organizar los actos conmemorativos en este día. Dos ejemplos ilustrativos son los siguientes:

En 1940 se celebra una misa funeral por los caídos de Hispanoamérica organizado por el ministerio de Asuntos Exteriores. El titular de la cartera en este momento es Juan Beigbeder Atienza (militar africanista). Su labor de reclutamiento de tropas en tierras africanas para el ejército franquista fue clave para el Bando Nacional durante la Guerra Civil Española. Tal y como afirman Alia, Del Valle y Morales (2008: 1079) "gracias a su profundo conocimiento de la psicología musulmana convenció a los moros de que la causa de Franco

${ }^{5}$ ROMERO, E., del ARCO, M. Y de MIGUEL, A., Los 90 ministros de Franco. Barcelona, Dopesa, 1971, p. 137. 
era más interesante y ventajosa para ellos que la causa republicana". Además comentan estos tres autores ${ }^{6}$ que:

(...) dada su brillante ejecutoria diplomática durante la Guerra Civil como mano derecha del general Jordana, Primer Ministro de Asuntos Exteriores de Franco, a la hora de comprometerse seriamente a los alemanes, así como al jalifa Muley Hassan y al gran visir de Tetuán, en la causa rebelde, podemos decir que fue el mejor diplomático de la Guerra Civil del bando rebelde.

Beigbeder es nombrado ministro de Asuntos Exteriores por el propio Ramón Serrano Suñer el 9 de agosto de 1939 y cesado de su cargo, así como relevado por el propio Suñer, el 16 de octubre de 1940. "Eran conocidas sus simpatías por los ingleses, por lo que su posición en los momentos en que estaba en alza el papel de Hitler no era muy cómoda" (Del Arco et al, 1971: 64).

En 1942 son varios los actos organizados por el ministerio de Asuntos Exteriores: exposición cartográfica, misa funeral por los Reyes Católicos y Cristóbal Colón y función de gala. En este momento es titular de la cartera Francisco Gómez Jordana (militar). Tal y como apuntan Del Arco et al (1971: 38) "el conde de Jordana ocupó dos puestos claves: la Vicepresidencia del Gabinete y la cartera de Asuntos Exteriores. Esto da una idea de la confianza que depositó Franco en este militar". Además recogen en su libro que "el paso de Gómez-Jordana por Exteriores lo han justificado los políticos de la época como una garantía de Franco cerca de las potencias aliadas, especialmente Inglaterra (...) El prestigio militar de Gómez-Jordana fue utilísimo para Franco". En agosto de 1944 fallece, lo que lleva a Franco a constituir un nuevo gobierno, ocupando su puesto en el Ministerio de Asuntos Exteriores José Félix de Lequerica.

Gregorio López-Bravo como ministro de Asuntos Exteriores y presidente del Instituto de Cultura Hispánica preside dos actos en 1972. López Bravo en 1959 es nombrado por Alberto Ullastres, ministro de Comercio en ese momento, Director General de Comercio Exterior. Gracias a sus méritos en este cargo público, en 1962 Franco lo nombra ministro de Industria. Fruto de este nombramiento "se veía reforzado el liderazgo económico del Opus Dei (...) [con] Gregorio López Bravo, un joven economista e ingeniero naval que era miembro de la Obra." (Lazo, 2008: 375). Cesa en este puesto en 1969 para pasar a ser el titular de la cartera de Asuntos Exteriores, ya que "la posición beligerante del ministro de Asuntos Exteriores, Fernando María Castiella, se había hecho insostenible, y en octubre de 1969 se produjo su cese fulminante y su sustitución por uno de los protegidos del almirante Luis Carrero Blanco" (Townson, 2009: 219).

Finalmente es cesado en 1973 tras la entrevista que mantiene con el Papa Pablo VI, en la que el ministro de Asuntos Exteriores acusa a su Santidad de "ser responsable de todos

\footnotetext{
${ }^{6}$ ALIA MiRANDA, F., DEL VAlle CALZADO, A. R. Y MORAleS ENCINAS, O. M. (Coords.), "La Guerra Civil en Castilla-La Mancha, 70 años después", en Actas del Congreso Internacional, Cuenca, Universidad de Castilla La Mancha, 2008, p. 1078.
} 
los desórdenes políticos y sociales que estaban teniendo lugar en España" (Lazo, 2008: 450). Tal y como comenta este autor (2008: 449), tanto él como el Opus Dei tenían "la absoluta convicción de que el clero hispano había llegado a una impía alianza secreta con los comunistas para derribar al régimen, y que el Vaticano debía, en consecuencia apoyar a Franco a fin de evitar el triunfo del ateísmo en el mundo".

También Laureano López Rodó en 1973 y Pedro Cortina en 1974 presiden los actos organizados, pero ya solo encargados de la cartera ministerial de política exterior y no como presidentes del Instituto de Cultura Hispánica. Ya que este cargo recae en S.A.R. el duque de Cádiz, que jura su cargo el 28 de julio de 1973 de manos del propio López Rodó. Desde este nombramiento, SS.AA.RR. los duques de Cádiz acuden a los actos organizados en el Día de la Hispanidad-Raza.

López Rodó era miembro del Opus Dei y uno de los "protegidos" por Carrero Blanco. De él comenta Bennassar (1996: 192) que estaba (...) "trabajando en un despacho cercano al de Carrero Blanco y siendo él mismo el consejero más escuchado por el Caudillo, López Rodó ejerció durante una década una influencia considerable en el gobierno de España".

Este ministro ocupó varios cargos dentro de los distintos gobiernos de la dictadura franquista. En 1956 es nombrado Secretario General Técnico de la Presidencia del Gobierno, en 1962 ocupa el puesto de Comisario del Plan de Desarrollo (dándole además el rango de subsecretario), cargo que se elevará a la categoría de ministro en 1965. Ya en 1973 Rodó pasa a ser el titular del departamento de Asuntos Exteriores. Lazo relata en su libro, "López Rodó, al frente de la Comisaría del Plan de Desarrollo es el personaje más popular del régimen, algo así como un rey Midas convirtiendo en oro cuanto tocaba"(2008: 374).

En cuanto al Ministerio de Asuntos Exteriores, durante el último año del régimen fue capitaneado por Pedro Cortina Mauri. "Pese a que el propio Franco se mostró favorable a la permanencia de López Rodó, Arias prefirió para la cartera de Exteriores a un diplomático de carrera, con muchos años de experiencia" (Gallego, 1987: 340). El Sr. Cortina preside un Te Deum y un acto académico en conmemoración del Día de la Hispanidad en 1974 y en 1975 forma parte de la mesa presidencial, también en un acto académico del Instituto de Cultura Hispánica.

El segundo ministerio que más se deja ver en los actos es el de Educación Nacional, más tarde con cambio de denominación, pasando a ser el Ministerio de Educación y Ciencia. Este cuenta con 31 apariciones, 18 en las que el ministro representante lo hace como concurrente en la presidencia y 5 veces presidiendo el acto.

Las presidencias ostentadas por el ministro de Educación Nacional ha recaído, en 4 de las ocasiones, en el Sr. Ibáñez Martín. En 1940 preside un acto académico de la Real Academia de Historia. Su presencia se ve justificada, además de por encabezar la cartera de Educación, el haber sido el catedrático de Geografía e Historia en el Instituto de San Isidro de Madrid. Las otras tres presidencias son compartidas con el ministro de Asuntos Exteriores, el 
Sr. Martín Artajo, en los actos relacionados con la comunidad universitaria que se han comentado con anterioridad.

Al igual que el ministro por entonces de Asuntos Exteriores, es propagandista católico y anteriormente a su nombramiento como ministro de Educación es llamado por Franco, junto a otros intelectuales, para emprender "una larga campaña en Hispanoamérica en vistas a propagar las ideas del nuevo régimen" (Romero et al., 1971: 72). Debido a esta labor participó en muchos actos propagandísticos. La presencia de Ibáñez Martín en los actos conmemorativos del Día de la Hispanidad-Raza se ve relacionada con el vínculo que este posee con el mundo hispanoamericano con el que mantuvo gran contacto siguiendo las directrices del Caudillo.

En cuanto a las ocasiones que ha concurrido en la presidencia, ha sido el ministro que más veces ha estado presente en la mesa presidencial. Entre estas nos encontramos que en 1946, en varios actos de la Inauguración de edificios del Consejo Superior de Investigaciones Científicas, se coloca a la derecha del Jefe del Estado. Esta posición privilegiada dentro de la mesa se explica porque fue uno de los iniciadores en la organización de este consejo, del que fue presidente hasta 1967.

Entre los actos en los que Ibáñez Martín ha estado presente en la presidencia, nos encontramos exposiciones cartográficas organizadas por el ministerio de Asuntos Exteriores, misas en honor a la Virgen del Pilar y sesiones extraordinarias del Instituto de Cultura Hispánica.

Ibáñez ha sido uno de los ministros del régimen franquista que más tiempo ha estado a cargo de una cartera ministerial; concretamente doce años, además de desempeñar otro puesto importante dentro del Régimen, la presidencia del Consejo de Estado. Justino Sinova (2006) describe la influencia que tenía en la toma de decisiones de su Ministerio, disponiendo que los hombres de su confianza ocuparan los principales puestos de la política de Prensa. Tusell ${ }^{7}$ se refiere a Ibáñez Martín como:

(...) un miembro de la derecha de la CEDA que en 1939 se adapta a las nuevas circunstancias políticas y que lo hace de nuevo a partir de 1944, lo que acabó permitiéndole sobrevivir como ministro hasta 1951 y como personaje relevante del régimen hasta el final de sus días.

Además su holgada vida política como ministro de Franco puede explicarse, basándonos en la teoría de Amando De Miguel (1975), porque Ibáñez era un monárquico menos acusado que su antecesor, Pedro Sainz. Este posicionamiento, algo más neutral, le permitió permanecer más tiempo en el poder.

Deteniéndonos en este departamento ministerial, cabe destacar a Julio Rodríguez Martínez, que ha presidido en una ocasión y concurrido en la mesa presidencial de otro acto.

${ }^{7}$ TUSELL, J., Franco y los católicos. Madrid, Alianza, 1984, p.33. 
Este estaba vinculado al Opus Dei y además de ser Procurador en Cortes entre 1971 y 1977, así como Consejero de de Educación y Economía Nacional durante la última etapa del Régimen, fue ministro de Educación y Ciencia entre junio de 1973 y enero de 1974 mientras que era presidente del Gobierno Carrero Blanco. Tras la muerte de este último, Rodríguez fue destituido. Debido al poco tiempo que permaneció en la cartera ministerial, disponemos de poca información al respecto.

Otra de las autoridades que podemos distinguir en este ministerio es Ruiz Giménez, que se presenta como uno de los que más veces ha concurrido en la mesa presidencial (con 5 ocasiones). Este en 1951 concurre en la presidencia de un acto académico del Instituto de Cultura Hispánica; anteriormente este ministro, entre 1946-1948, había sido el primer director de este instituto. Durante su mandato en el mismo tuvo a sus órdenes como colaboradores a unos jóvenes Manuel Jiménez Quílez, Alfredo Sánchez Bella y Manuel Fraga, que pertenecían entonces a Acción Católica Propagandística. Además, Ruiz Giménez por entonces también trabajaba en el Instituto de Estudios Políticos (IEP), en el que participaba en la redacción del Fuero de los Españoles y la Ley de Sucesión.

Entre 1948 y 1951 ejerce como embajador ante la Santa Sede durante las negociaciones del Concordato firmado en 1953. La intervención de Ruiz-Giménez "en la Santa Sede era muy beneficiosa para el régimen, gracias a su amistad con los obispos Montini y Tedeschini, a su labor entre la influyente curia romana y a sus buenas relaciones con las asociaciones italianas de apostolado seglar" (Muñoz Soro, 2006: 267-268).

Posteriormente en 1951 es llamado para ocupar la cartera de Educación. Como comenta Muñoz Soro (2006: 268) "con Ruiz-Giménez el Ministerio de Educación Nacional seguía vinculado a la 'familia católica' (en realidad más que con su predecesor, Ibáñez Martín, un franquista antes que nada)".

Este ministro entre 1952, 1953 y 1955 forma parte de la mesa presidencial de diferentes actos académicos en conmemoración del Día de la Hispanidad.

El mandato de Ruiz Giménez se extiende entre 1951 y 1956. Franco lo destituye al acusarle "de haber permitido y fomentado la apertura internacional -denunciada por el Opus Dei y los obispos- que llevó al estallido de los disturbios. Esto a su vez derivó en una limpieza general de cuantos habían colaborado con el ministro" (Romero et al., 1971: 351).

El tercer ministerio que más presencia tiene en los actos analizados en la celebración de este día del mundo hispánico, es el de la Gobernación, con 30 ocasiones. De las cuales 9 lo hace en la mesa presidencial y 6 presidiendo el acto.

Entre los años 1957 y 1969 el Ministerio de la Gobernación está capitaneado por Camilo Alonso Vega. Este pertenece al estamento militar y en esa época era coronel honorario de la Guardia Civil, anteriormente había sido nombrado Director General de la Guardia Civil (1943-1957); lo que explica su presencia en las funciones religiosas en honor a la patrona de la Benemérita. De hecho, Alonso Vega preside 3 funciones religiosas en 1959, 
1960 y 1961 . Además en 1967 preside la clausura de un Congreso en representación del Jefe del Estado; lo que representa la confianza que el Caudillo deposita en este ministro.

En 1957, con el significativo cambio de gobierno, Franco pone al mando a 7 ministros que son militares, frente a los 17 que conforma la Junta de Gobierno. Camilo Alonso Vega "es amigo personal y compañero de armas del General Franco, era una figura mítica en aquella época. Por su historial militar y la gran confianza de que gozaba ante Franco"(Vázquez, 1999: 191). Lazo (2008: 184) dice de él que "ha sido el hombre duro, la encarnación de la fuerza, durante los doce últimos años de la historia del Régimen de Franco". Es tal la relación que le une al Caudillo que en 1969 cuando es destituido del cargo de ministro es ascendido directamente a Capitán General, rango militar solo alcanzado en vida por Franco y Agustín Muñoz Grandes.

La concurrencia en la presidencia de este ministro, así como su asistencia se basa principalmente en funciones religiosas, a las que incluso acude su esposa Ramona Rodríguez Bustelo, amiga íntima de Carmen Polo, la esposa del Jefe del Estado.

El titular del Ministerio de la Gobernación en 1944 es Blas Pérez González, el cual preside una función religiosa en honor a la Virgen del Pilar, patrona de la Guardia Civil. Su presidencia, compartida con doña Carmen Polo, no se puede explicar por la relación de su ministerio con la Guardia Civil. Pero si es una persona que como comenta Lazo (2008: 111) "contó con la confianza y el aliento total de Franco llegándose a decir, con motivo de su cese, que había tenido opción para continuar formando parte del Gobierno. Ello ratifica la confianza que gozaba cerca del Jefe del Estado". Continúa Lazo comentando que en ese momento Pérez González jugó un papel muy importante "en la depuración y represión de los elementos políticos partidarios de la República e incluso de los enemigos internos del sistema". Años más tarde el propio Franco admite la eficacia de la labor realizada por este ministro, el papel clave que jugó y opina de él: "el ministro de la Gobernación, don Blas Pérez González, me parece estupendo, es de lo más leal y vale mucho; es un abogado de primera fila...Tengo gran afecto a este ministro" (Franco Salgado-Araújo, 1976: 182-183).

Blas Pérez era el encargado del aparato represivo del Régimen, tanto para salvaguárdalo del bando izquierdista como para resguardar la Jefatura del Estado de los ataques de las familias internas disconformes, la Falange radical y monárquicos partidarios de don Juan de Borbón. Desde 1942 hasta 1956 su presencia en los actos celebrados en conmemoración del Día de la Hispanidad es casi regular. Concurriendo en la presidencia de estos los años 1943, 1947, 1954, 1955 y 1956 en funciones religiosas y sesiones académicas. Incluso en dos de los años mencionados acude como ministro de jornada.

Ramón Serrano Suñer en 1940 como ministro de la Gobernación y Presidente de la Junta Política preside un acto: la exposición civilizadora de España en el mundo. Romero et al. (1971: 33) se refieren a él como "uno de los creadores del régimen nacido como consecuencia del 18 de Julio, o cuando menos, fue el que le dio consistencia jurídicopolicita", así como "el hombre fuerte en la difícil década de los cuarenta" y "el principal 
cerebro de unificación falangista". El acto que ha sido analizado corresponde a la época del punto álgido de Falange como familia fuerte dentro del Régimen.

Ramón Serrano Suñer o también llamado popularmente como "el cuñadísimo" por ser ese su parentesco con el Jefe del Estado, fue ministro de la Gobernación y de Asuntos Exteriores así como colaborador principal de Franco en el período más decisivo del Régimen, cuando se establecen sus fundamentos doctrinales e institucionales y está en juego la neutralidad o beligerancia de España durante la Segunda Guerra Mundial.

Su carrera política cesó tras los incidentes protagonizados entre falangistas y carlistas en el santuario de la Virgen de Begoña en Bilbao. Este acto estaba presidido por el General Varela (ministro del Ejército), en quien el carlismo veía apoyo dentro del Gobierno. Como consecuencia de estos sucesos, los falangistas responsables del atentado fueron condenados por un tribunal militar y dos generales que eran ministros, Varela y Galarza, presentaron su dimisión por disconformidad con el Caudillo. En respuesta a estos acontecimientos, como relata Fernández-Longoria ${ }^{8}$, el ministro Carrero Blanco convence a Franco para:

(...) eliminar a Serrano Suñer, ya que de lo contrario los militares y el resto de fuerzas conservadoras pensarían que la Falange había resultado vencedora y que Franco no controlaba ya la situación. Franco no dudó en dar dicho paso al estar resentido con su cuñado, que ya había perdido su confianza.

De esta manera "se consumaba la derrota política de Serrano Suñer, que había gozado de amplios poderes desde su nombramiento como ministro de Gobernación y de la plena confianza de Franco durante la mayor parte de su labor gubernativa" (Tusell, 1984: 326).

Agustín Muñoz Grandes preside dos actos en 1962 y 1963 como vicepresidente del Gobierno. Se tratan de un Te Deum de acción de gracias celebrado en la Iglesia del Espíritu Santo del Consejo Superior de Investigaciones Científicas (Madrid) y una función religiosa en honor a la Virgen del Pilar.

La presencia de este ministro en muchos de los actos celebrados durante su mandato como vicepresidente del gobierno se explica porque:

(...) la confianza y amistad, en la etapa final de sus vidas, entre Franco y Muñoz Grandes era muy grande.(...) el capitán general y jefe del Alto Estado Mayor se había convertido, por el transcurrir del tiempo, en el más seguro y fiel valedor del franquismo.

\footnotetext{
${ }^{8}$ FERNÁNDEZ-LONGORIA, M., "La Diplomacia Británica y La Caída De Serrano Suñer. Espacio, Tiempo y Forma". Serie V, Historia Contemporánea, 16, 2004, pp. 253-268, p. 264 . Recuperado de http://espacio.uned.es/revistasuned/index.php/ETFV/ article/view/3101
} 
Además concurre en la presidencia de una función religiosa en 1956, pero como ministro del Ejército. Tal era la fe depositada en Muñoz Grandes por parte del Generalísimo, que este último pensaba relevar su poder en este ministro. Togores recoge la revelación de la "intención" que tenía el Caudillo en la biografía de Muñoz Grandes (2007)

En estos años [1957] la confianza de Franco en Muñoz Grandes es absoluta. Cuando iba a ser anestesiado para ser operado como consecuencia de la herida que había sufrido en una mano - al reventarle una escopeta en una cacería-, le dijo a Alonso Vega que si le pasaba algo que tomase el mando Muñoz Grandes, cosa lógica ya que era el único capitán general del Ejército español, aparte del propio Franco.

Cabe comentar que Muñoz Grandes ostenta varios cargos militares y políticos a lo largo del régimen franquista:

En el gobierno de 1939 fue nombrado por el Caudillo como ministro secretario general del Movimiento y jefe de las Milicias de Falange Española Tradicionalista y de las J.O.N.S. Poco tiempo después de este nombramiento tiene que cesar en su puesto porque es nombrado gobernador militar del Campo de Gibraltar, dada la llegada de las tropas alemanas.

En julio de 1942 es nombrado comandante en jefe de la unidad de voluntarios españoles (División Azul) que combaten al lado de las tropas de Hitler. A su regreso a España en 1943, le ascienden a teniente general y le nombran jefe de la Casa Militar del Jefe del Estado y en 1945 se le confía la capitanía general de la I Región Militar. En el año 1951 es nombrado ministro del Ejército y llegados a 1957 es ascendido a capitán general, categoría dentro del Ejército Español solamente ostentado por el Generalísimo. La culminación de su carrera política llega en 1962 cuando es nombrado vicepresidente del Gobierno, cargo nombrado por primera vez en la historia del franquismo.

Su carrera militar y política, las numerosas condecoraciones que recibió, así como la amistad que lo unía al Jefe del Estado lo llevó a ser una de las personas más apegadas a Franco y en una de las que más confío. Prueba de ello la encontramos en la inauguración del Valle de los Caídos, donde el Caudillo comenta a Navarro Rubio: "Si Muñoz Grandes viviera para cuando yo falte, tiene la suficiente talla para ser nombrado regente" (Gil, 1981: 113). Aunque dicho apego, se traduce para muchos como una cierta desconfianza por parte del Generalísimo hacía Muñoz Grandes. Esta idea es recogida por Lazo (2008: 369): "es muy posible que desde los lejanos tiempos de la División Azul Franco le tuviese un poco de miedo, sospechando de él una excesiva influencia sobre parte del Ejército y de la Falange". Aún así el Jefe del Estado mostraba su aprecio hacia este ministro y lo hizo público, tanto en sus actuaciones como a través de sus palabras.

Del Ministerio de la Marina encontramos a dos autoridades que están presentes en la presidencia de los actos conmemorativos en este día. Estos son:

\footnotetext{
${ }^{9}$ TOGORES, L. E., Muñoz Grandes..., p. 354.
} 
El almirante Abárzuza, que como ministro de la Marina preside, acompañado del ministro de la Gobernación en una ocasión y del Ejército en otra, funciones religiosas en honor de la Virgen del Pilar en el templo de San Francisco el Grande en Madrid. Prueba de la confianza que el Jefe del Estado depositó en este militar la encontramos en la asistencia de este, en representación del Jefe del Estado, a la boda de SS.AA.RR. los Príncipes Don Juan Carlos y Doña Sofía. Tal y como narra Preston (2012), Franco rechazó la invitación a la boda, pero informó a Don Juan Carlos de que "estaría debidamente representado por el ministro de la Marina", el contralmirante Felipe Abárzuza Oliva, el cual viajaría a Atenas a bordo del crucero "Canarias", el buque insignia de la Marina española.

Por otro lado, tenemos al almirante Salvador Moreno que concurre en la presidencia en 3 ocasiones. En 1943 en la inauguración de la Ciudad Universitaria y en 1956 en una función religiosa y en una sesión académica del Instituto de Cultura Hispánica. Además dos autoridades lo han representado en actos a los que no ha podido acudir, el almirante Bastarreche (1940) y el vicealmirante Rapalla (1944).

Romero et al. (1971: 68) en su libro trascriben así lo que se ha comentado sobre el almirante Moreno: "en Consejo de Ministros intervino muy activamente en temas meramente políticos, y de ahí que en las esferas políticas se haya comentado, con insistencia, su fuerte posición en el Gobierno".

Cabe destacar, por último, la presencia de Pedro Gual Villalbí en la concurrencia de tres actos como ministro sin cartera. En 1957 en una sesión académica, celebrada en el Salón del Ciento de Barcelona, situándose este en un lugar privilegiado, a la derecha de Franco. En 1960 acude como concurrente en la presidencia a una misa en honor a la Virgen del Pilar en San Francisco el Grande (Madrid). Por último, en 1961, también asiste a una misa en Madrid, en el mismo templo nombrado anteriormente y lo hace concurriendo el último en una presidencia lineal, por detrás del ministro de la Gobernación, del Aire, de Industria y del Secretario General del Movimiento.

Romero et al. (1971: 182) explican la relevancia de la llegada al gobierno de este ministro:

La figura del Ministro sin Cartera reaparece en la persona de un economista catalán, Pedro Gual Villalbí, presidente del Consejo de Economía Nacional. Este hecho es muy significativo, da la pauta de la creciente importancia que Franco va a darle a los ministros «económicos».

Además, como relata Muniesa (2005), la entrada de este ministro simbolizaba la incorporación de la "gran burguesía catalana" en el Gobierno.

Romero et al. (1971) concluyen que, a pesar de que Villalbí estuvo una época prolongada en el Gobierno, incluso en un cargo como "algo así como en un superministerio", este no se apegó a ninguna ideología política, ni dejo clara su inclinación hacia ningún lado. 
Esta larga permanencia en el poder se debe, en gran parte, como explica Bennassar (1996: 288) a que "el Caudillo tenía cuidado en situar en cada combinación ministerial personalidades sin opción política claramente definida, que él podía inclinar a su gusto en un sentido o en otro a fin de orientar las decisiones para tener la mayoría". Este fue el caso de Pedro Gual Villalbí, entre otros.

\subsection{Resultados del análisis de los actos oficiales del Día de SAN JOSÉ ARTESANO}

\begin{tabular}{|c|c|c|c|}
\hline $\begin{array}{c}\text { MINISTROS Y } \\
\text { SUBSECRETARIOS }\end{array}$ & $\begin{array}{c}\text { № DE VECES QUE } \\
\text { ACUDEN A LOS } \\
\text { ACTOS CELEBRADOS }\end{array}$ & $\begin{array}{c}\text { № DE VECES QUE } \\
\text { CONCURREN EN LA } \\
\text { PRESIDENCIA }\end{array}$ & $\begin{array}{c}\text { № DE VECES QUE } \\
\text { PRESIDEN LOS ACTOS } \\
\text { CELEBRADOS }\end{array}$ \\
\hline Presidente del Gobierno & $\mathbf{3}$ & 2 & 0 \\
\hline Luis Carrero Blanco & 3 & 2 & 0 \\
\hline Vicepresidente del Gobierno & 3 & 3 & 0 \\
\hline Agustín Muñoz Grandes & 1 & 1 & 0 \\
\hline Luis Carrero Blanco & 2 & 2 & 0 \\
\hline $\begin{array}{c}\text { Subsecretario de la } \\
\text { Presidencia }\end{array}$ & 6 & 1 & 0 \\
\hline Luis Carrero Blanco & 6 & 1 & 0 \\
\hline Gobernación & 9 & 7 & 0 \\
\hline Camilo Alonso Vega & 7 & 6 & 0 \\
\hline Tomás Garicano Goñi & 1 & 1 & 0 \\
\hline Carlos Arias Navarro & 1 & 0 & 0 \\
\hline Asuntos Exteriores & 3 & 1 & 0 \\
\hline Fernando María Castiella & 3 & 1 & 0 \\
\hline Ejército & 4 & 0 & 0 \\
\hline $\begin{array}{c}\text { Antonio Barroso Sánchez- } \\
\text { Guerra }\end{array}$ & 1 & 0 & 0 \\
\hline Pablo Martín Alonso & 1 & 0 & 0 \\
\hline Camilo Menéndez Tolosa & 2 & 0 & 0 \\
\hline Marina & 5 & 1 & 0 \\
\hline Felipe Abárzuza Oliva & 1 & 0 & 0 \\
\hline Pedro Nieto Antúnez & 4 & 1 & 0 \\
\hline Aire & 4 & 1 & 0 \\
\hline $\begin{array}{c}\text { José Rodríguez y Díaz de } \\
\text { Lecea }\end{array}$ & 2 & 0 & 0 \\
\hline José Lacalle Larraga & 2 & 1 & 0 \\
\hline Educación Nacional & 3 & 2 & 0 \\
\hline Manuel Lora Tamayo & 2 & 1 & 0 \\
\hline José Luis Villar Palasí & 1 & 1 & 0 \\
\hline Obras Públicas & 3 & 1 & 0 \\
\hline Jorge Vigón Suerodíaz & 3 & 1 & 0 \\
\hline Industria & 6 & 1 & 0 \\
\hline Joaquín Planell Riera & 2 & 0 & 0 \\
\hline Gregorio López Bravo & 4 & 1 & 0 \\
\hline Comercio & 2 & 0 & 0 \\
\hline Alberto Ullastres Calvo & 2 & 0 & 0 \\
\hline Agricultura & 6 & 2 & 0 \\
\hline Cirilo Cánovas García & 4 & 1 & 0 \\
\hline Alfonso Díaz Ambrona & 2 & 1 & 0 \\
\hline
\end{tabular}




\begin{tabular}{|c|c|c|c|}
\hline $\begin{array}{c}\text { MINISTROS Y } \\
\text { SUBSECRETARIOS }\end{array}$ & $\begin{array}{l}\text { № DE VECES QUE } \\
\text { ACUDEN A LOS } \\
\text { ACTOS CELEBRADOS }\end{array}$ & $\begin{array}{c}\text { № DE VECES QUE } \\
\text { CONCURREN EN LA } \\
\text { PRESIDENCIA }\end{array}$ & $\begin{array}{c}\text { № DE VECES QUE } \\
\text { PRESIDEN LOS ACTOS } \\
\text { CELEBRADOS }\end{array}$ \\
\hline Vivienda & 8 & 4 & 0 \\
\hline $\begin{array}{c}\text { José María Martínez y } \\
\text { Sánchez Arjona }\end{array}$ & 8 & 4 & 0 \\
\hline Hacienda & 2 & 0 & 0 \\
\hline Mariano Navarro Rubio & 2 & 0 & 0 \\
\hline Trabajo & 19 & 4 & 3 \\
\hline $\begin{array}{l}\text { José Antonio Girón de } \\
\text { Velasco }\end{array}$ & 2 & 1 & 0 \\
\hline Fermín Sanz Orrío & 8 & 1 & 2 \\
\hline Jesús Romeo Gorría & 5 & 1 & 1 \\
\hline $\begin{array}{c}\text { Licino de la Fuente y de la } \\
\text { Fuente }\end{array}$ & 4 & 1 & 0 \\
\hline Justicia & 2 & 1 & 0 \\
\hline Antonio Oriol y Urquijo & 2 & 1 & 0 \\
\hline Información y Turismo & 5 & 1 & 0 \\
\hline Gabriel Arias Salgado & 2 & 0 & 0 \\
\hline Manuel Fraga Iribarne & 3 & 1 & 0 \\
\hline $\begin{array}{c}\text { Secretario Gral. Del } \\
\text { Movimiento }\end{array}$ & 15 & 9 & 2 \\
\hline Raimundo Fernández Cuesta & 1 & 0 & 0 \\
\hline José Solís Ruiz & 14 & 9 & 2 \\
\hline Relaciones Sindicales & 4 & 1 & 0 \\
\hline $\begin{array}{c}\text { Enrique García-Ramos y } \\
\text { Cellalbo }\end{array}$ & 3 & 1 & 0 \\
\hline Alejandro Fernández Sordo & 1 & 0 & 0 \\
\hline $\begin{array}{c}\text { Ministro sin Cartera } \\
\text { Pedro Gual Villalbí }\end{array}$ & 1 & 0 & 0 \\
\hline Subsecretario de Trabajo & 5 & 1 & 1 \\
\hline Jesús Romeo Gorría & 1 & 1 & 0 \\
\hline Cristóbal Graciá & 2 & 0 & 1 \\
\hline Sin constancia del nombre & 2 & 0 & 0 \\
\hline
\end{tabular}

Cuadro 4: Ministros que más asisten a los actos del Día de San José Artesano, los presiden o forman parte de sus presidencias.

Fuente: Elaboración propia. 


\begin{tabular}{cccc} 
NOMBRE Y CARGOS & $\begin{array}{c}\text { No DE VECES QUE } \\
\text { ACUDE A LOS ACTOS } \\
\text { CELEBRADOS }\end{array}$ & $\begin{array}{c}\text { No DE VECES QUE } \\
\text { CONCURRE EN LA } \\
\text { PRESIDENCIA }\end{array}$ & $\begin{array}{c}\text { No DE VECES QUE } \\
\text { PRESIDE LOS ACTOS } \\
\text { CELEBRADOS Carrero Blanco }\end{array}$ \\
$\begin{array}{c}\text { Como Presidente del Gobierno, } \\
\text { Vicepresidente del Gobierno y } \\
\text { Subsecretario de la Presidencia } \\
\text { Jesús Romeo Gorría }\end{array}$ & 11 & 5 & 0 \\
$\begin{array}{c}\text { Ministro de Trabajo y subsecretario del } \\
\text { mismo departamento }\end{array}$ & 6 & 2 & 1 \\
\hline
\end{tabular}

Cuadro 5: Autoridades con varios cargos ministeriales que más asisten, presiden o concurren en las presidencias de los actos del Día de San José Artesano.

Fuente: Elaboración propia.

En cinco ocasiones asisten el Presidente del Gobierno y los ministros a los actos celebrados en esta fecha, pero sin especificarse cuáles son los departamentos ministeriales. La posición que toman en estas ocasiones es o bien cerca del palco de honor o detrás del palco presidencial.

Los ministerios que tienen más presencia en la celebración de esta fiesta son, lógicamente por la naturaleza de la celebración, el de Trabajo (19 ocasiones) y el de la Secretaría General del Movimiento (15 ocasiones). Entre los actos celebrados, como se ha comentado con anterioridad, podemos encontrar:

1. Entregas de trofeos y diplomas del IV Concurso Internacional de Formación Profesional Obrera y X Concurso Nacional de Formación Profesional Obrera.

2. Funciones religiosas en honor a San José Obrero organizadas por la Delegación Nacional de Sindicatos.

3. Juegos Deportivos.

4. Demostraciones Sindicales de Teatro, Música y Danza organizadas por Educación y Descanso, una de las Obras de la Organización Sindical española.

El ministro que más ha aparecido en la presidencia de los actos mencionados es José Solís Ruiz, como ministro secretario general del Movimiento, 2 veces presidiendo y un total de 9 ocasiones concurriendo en la mesa presidencial. Ha estado presente en todos los actos que han tenido lugar entre 1957 y 1969 que se han celebrado con motivo del Día de San José Artesano. Es sabido que "la máxima proyección sindical del falangismo tuvo lugar bajo José Solís Ruiz, en buena parte modernizador de los sindicatos verticales" (Alvar, 2001: 271).

Solís, al terminar la guerra civil, ingresó por oposición en el Cuerpo Jurídico Militar a la vez que se convirtió en secretario técnico sindical. En 1944 se le nombró vicesecretario general de Ordenación Social. Con este cometido participó en las primeras elecciones del sindicalismo vertical y convocó los primeros congresos nacionales de trabajadores. Más 
tarde, en 1948, fue nombrado gobernador civil y jefe provincial del Movimiento de Pontevedra y, posteriormente, de Guipúzcoa. Fue en 1951 cuando es nombrado delegado nacional de Sindicatos y Consejero del Reino. Además Solís también fue procurador en Cortes durante ocho legislaturas. Su carrera política se vio ensalzada con el ascenso a ministro Secretario General del Movimiento en 1957. "En su persona se funden, por vez primera, los cargos de delegado nacional de Sindicatos y ministro secretario general del Movimiento. En este último puesto le toca vivir el ocaso falangista" (Romero et al., 1971: 211). Tal y como expone Lazo ${ }^{10}$ :

A pesar de ser oficialmente el responsable directo del Partido único, no se engañaba a sí mismo y era consciente de que tal partido solo existía sobre papel y en la imaginación de los nostálgicos; en cambio, los Sindicatos Verticales seguían siendo una poderosa maquinaria burocrática que manejaba ingentes cantidades del dinero de los presupuestos.

Pero además, Solís es el más importante "Regencialista" en la formación del Gobierno de 1957, característica importante para el propósito del Caudillo; frenar las pretensiones de los monárquicos.

Durante los doce años que fue ministro se aprobó la Ley de Convenios Colectivos (1959), participó en la elaboración de las Leyes Fundamentales y en el Estatuto de Asociaciones Políticas. En el reajuste gubernamental de 1969 deja su mandato, para ser retomado en 1975, sucediendo a Fernando Herrero Tejedor. Su último puesto en política nacional lo culmina en el Gobierno de Arias Navarro como ministro de Trabajo.

En el Ministerio de Trabajo, son dos los nombres que destacan por haber presidido actos del día de San José Artesano: Fermín Sanz Orrío y Jesús Romeo Gorría. Este último en calidad tanto de ministro como de subsecretario de dicho departamento.

Sanz Orrío preside dos actos, localizados en 1957 en un acto académico y en 1961 en la bendición de la sede del Ministerio de Trabajo bajo el patronazgo de San José Artesano. Además de asistir a las diferentes Demostraciones Sindicales celebradas con motivo de esta fecha.

Se trata de un falangista con orígenes próximos al carlismo que accedió al gobierno el 25 de febrero de 1957, formando parte de un Gobierno de "técnicos" desideologizado. Como comenta Lazo (2008: 369), en esta nueva formación había el mismo número de falangistas que en los gobiernos anteriores, pero con una particularidad primordial: "estos camisas azules residuales no tenían ya otro ideal político sino la obediencia a Franco". Tuñón de Lara coincide con Lazo, en cuanto a la reducción de poder que cada vez más

\footnotetext{
${ }^{10}$ LAZO DÍAZ, A., Una Familia Mal Avenida: Falange, Iglesia y Ejército. Madrid, Síntesis, 2008, p. 370.
} 
experimentaba la Falange, cuando comenta que "la sustitución de Girón por el borroso Sanz Orrío significaría una pérdida de poder para la Falange". ${ }^{11}$

Romeo Gorría es teóricamente falangista, pero próximo al Opus Dei. Comienza su carrera dentro de la administración del Estado en 1957, cuando fue elegido por Sanz Orrío para ocupar la subsecretaría del ministerio de Trabajo, posteriormente, en 1962 es nombrado ministro de Trabajo, sucediendo a este. El 29 de octubre de 1969 cesa en su cargo y poco después es nombrado presidente de Iberia Líneas Aéreas de España. Mientras ocupó el puesto de subsecretario del Ministerio de Trabajo, en 1957, ya formó parte de la presidencia en un acto académico con motivo de la festividad de San José Artesano. Y durante su mandato como ministro de Trabajo, en 1963, presidió un acto y en 1968 concurrió, junto a otros ministros, en la presidencia de la XI Demostración Sindical de Educación y Descanso. Además de haber asistido a numerosos actos representando a la cartera de Trabajo.

Entre las autoridades que concurren en las presidencias de los actos celebrados en conmemoración del día de San José Artesano, encontramos a Luis Carrero Blanco. Se trata de "(...) uno de estos hombres que goza de la plena confianza de Franco. Si en la política española puede hablarse de "brazos derechos» o de "brazos izquierdos» del Caudillo, Carrero es, sin duda, uno de ellos"(Romero et al., 1971: 151).

Durante el primer franquismo, la trayectoria política de Carrero Blanco se define por distintos tramos. Fue subsecretario de la Presidencia del Gobierno y consejero nacional de FET-JONS desde 1940. En 1945 fue nombrado vicepresidente segundo de las Cortes Españolas, hasta que con la configuración del nuevo Gobierno en 1951, su cargo se elevó al rango de ministro. Tusell (1993: 452-453) califica a Carrero de "indudable número dos del Régimen" con una complementariedad perfecta con Franco que se mantuvo a lo largo del tiempo.

También aparece en puestos destacados Camilo Alonso Vega, ministro que ya ha sido comentado con anterioridad en los actos celebrados en el día de la Hispanidad-Raza. En el caso de la celebración del día de San José Artesano, Alonso Vega ha concurrido en la mesa presidencial en 6 ocasiones como ministro de la Gobernación.

Por último, el ministro que más se deja ver en los actos conmemorativos de San José Artesano es José María Martínez y Sánchez Arjona, representando al Ministerio de la Vivienda. "Es un falangista de siempre que ha prestado dilatados servicios al Régimen en numerosos cargos y puestos. (...) Por su labor en el sector sindical, Franco le elige el 20 de

\footnotetext{
${ }^{11}$ Citado por ZAFRILLA TOBARRA, R., Universidades laborales: un proyecto educativo falangista para el mundo obrero (1955-1978). Aproximación histórica. (Tesis doctoral). Universidad de Castilla La Mancha, Cuenca, 1998, pp. 198-199.
} 
abril de 1960 para asumir el ministerio de la Vivienda, departamento generalmente asignado a militantes de Falange" (Romero et al., 1971: 237). Por lo que, tal y como relata Preston ${ }^{12}$ :

Arrese fue sustituido por un anodino falangista amigo de Solís (...). López Rodó halló en él un compañero cooperativo y Navarro Rubio, igualmente empeñado en «despolitizar» la política y convertirla en pura administración técnica, lo vio como «un ministro normal que hablaba de números».

Sánchez Arjona tuvo una dilatada carrera política, ya que permaneció en su cartera ministerial casi 10 años. En los actos analizados concurre en la presidencia de las Demostraciones Sindicales de Educación y Descanso celebradas en el Santiago Bernabéu y en el Camp Nou en 1960, 1961, 1966 y 1968. Además de acudir a otros tantos actos celebrados en honor a San José Artesano.

\section{CONCLUSIONES}

En los actos analizados en los dos días estudiados, coinciden los ministros que más presiden o están presentes en las mesas presidenciales con los que más acuden a los actos. Pero en este análisis también se han resaltado a aquellos que, aunque no forman parte de los que más han acudido, sí están entre los que más han presidido los actos. Es el caso de López Rodó, López- Bravo, Cortina Mauri, Serrano Suñer, Rodríguez Martínez; este dos últimos, aunque solo han presidido un acto, han concurrido en la presidencia en otra ocasión.

En algunas ocasiones, la aparición de los ministros que representan a un determinado ministerio lo solicita la propia naturaleza de la fecha. Es el caso del Día de la HispanidadRaza, en la que el Ministerio de Asuntos Exteriores juega un papel muy importante en los actos que conmemoran esta fecha, al estar vinculado con las relaciones exteriores con Iberoamérica o con organismos como el Instituto de Cultura Hispánica. También podemos citar el Ministerio de Trabajo en el Día de San José Artesano. Pero en otras ocasiones la aparición de otros ministerios, incluso el presidir o concurrir en la presidencia de los actos, no está justificada por el vínculo que pueda unir al departamento ministerial que representa la autoridad que asiste al acto con la celebración de la fecha, sino que más bien está relacionada con otros cargos que ocupan estas autoridades. Es el caso de Camilo Alonso Vega, que asiste a actos del Día de la Hispanidad en calidad de, además de ministro de la Gobernación, coronel honorario de la Guardia Civil, así como Serrano Suñer que acude a los actos de este día como ministro de Asuntos Exteriores y presidente del Consejo de la Hispanidad o José Solís que asiste a las Demostraciones Sindicales celebradas en el Primero de Mayo como ministro Secretario General del Movimiento, además de delegado nacional de Sindicatos.

A estas veces, hay que sumarles otras en las que el ministerio representado no presenta ningún vínculo aparente con el acto o el día conmemorado. Localizamos en este

\footnotetext{
12 PRESTON, P., Franco: Caudillo de España. Barcelona, DeBolsillo, 2011, p.115.
} 
caso al Ministerio de la Gobernación, al de la Marina o la Vicepresidencia del Gobierno en algunos actos del Día de la Hispanidad-Raza o al Ministerio de la Gobernación, de la Vivienda o Vicepresidencia del Gobierno en el Día de San José Artesano.

Tras haber realizado un análisis sobre la presencia de los ministros en los actos que conmemoran las dos fechas estudiadas, hemos observado una importante coincidencia gracias a los testimonios de varios autores que hemos recogido. Normalmente los ministros que más acuden, así como los que se colocan en posiciones más privilegiadas, presidiendo el acto o concurriendo en la presidencia, poseen una especial relación con el Jefe del Estado y en ocasiones están amparados incluso por algunos presidentes, vicepresidentes o subsecretarios de la presidencia como Carrero Blanco o Arias Navarro.

En unos casos cuentan con la simpatía o el beneplácito de Franco por ejercer, de alguna forma, una influencia directa sobre algún grupo o institución concreta de la que el Jefe del Estado podía obtener alguna utilidad o beneficio para el Régimen. Encontramos en este grupo a los ministros Castiella y Ruiz Giménez y sus excelentes relaciones con la Santa Sede, Beigbeder y sus actuaciones con el objetivo de conseguir el apoyo de los moros para la causa del Caudillo, y por último a Gómez Jordana y su posicionamiento cercano a las potencias aliadas que beneficiaban al régimen franquista. En otros casos, la afinidad que tenía el Jefe del Estado con ciertos ministros estaba basada en que estos no poseían una ideología política muy marcada, es decir, se encontraban en un posicionamiento bastante neutral y estaban al servicio del Generalísimo antes que al de la "familia" política con la que poseían ciertos vínculos. Podemos recoger en esta causa a Ibáñez Martín, Gual Villalbí y Sanz Orrío. Por otro lado, observamos al conjunto conformado por aquellos en que su presencia en los actos, en muchos casos, coincide con las etapas en las que las familias políticas que son más afines pasan por su periodo de mayor auge. Entre estos nos podemos encontrar al falangista Serrano Suñer, a López-Bravo y López Rodó, ambos protegidos por Carrero Blanco y pertenecientes al Opus Dei y a Martín Artajo, líder de Democracia Cristiana. Por último, recogemos a los ministros que poseían grandes lazos de amistad que les unían a Franco, considerados por este como personas muy leales a él, y como consecuencia al Régimen. Este círculo cerrado e íntimo está formado por autoridades como Muñoz Grandes, Alonso Vega, Blas Pérez o Carrero Blanco.

Además de esta coincidencia, encontramos otro hecho que consolida la idea de que cuentan con una posición privilegiada en los actos celebrados aquellos ministros que, por alguna de las circunstancias anteriormente descritas, se encuentran especialmente vinculados al Jefe del Estado. Estos son los casos en los que la ubicación de los ministros no siguen las directrices marcadas por la reglamentación vigente durante el franquismo en materia de precedencias y ordenación de autoridades, sino que la ubicación de estos está basada en un criterio subjetivo, beneficiando la posición que ocupan unas autoridades y perjudicando, por consecuencia, a otras. Podemos citar los siguientes ejemplos:

En 1943, en un acto que conmemoraba el Día de la Hispanidad-Raza, en una presidencia oyendo misa de campaña en la Ciudad Universitaria de Madrid se ubica al ministro de la Marina, el almirante Moreno, en el primer puesto después de Franco en una 
presidencia lineal o lateral con ordenación correlativa, por encima del lugar que le corresponde, además de encontrarse otras irregularidades en la ordenación de esta presidencia.

En un acto celebrado en el paraninfo de la Universidad de Granada en el Día de la Hispanidad-Raza en 1952, el ministro de Educación Nacional, Ruiz Giménez, ocupa el primer puesto a la derecha del Jefe del Estado, varios puestos por encima del ministro de Asuntos Exteriores Martín Artajo, incumpliendo por lo tanto la normativa vigente y situándose en un puesto considerado de honor. Además, en una sesión académica del Instituto de Cultura Hispánica en 1955, Ruiz Jiménez, representando al Ministerio de Educación Nacional, está ubicado por encima del ministro de Obras Públicas, el conde de Vallellano, no siguiendo de esta manera las directrices de la orden de 1951 sobre la prelación de los distintos ministerios.

Como último ejemplo, presentamos una sesión académica del IV Congreso Histórico Municipal Interamericano en 1957, donde erróneamente el ministro sin cartera, Gual Villalbí, se coloca en la mesa presidencial por encima del ministro de Educación, el Sr. Rubio García.

Con la exposición de estos casos en concreto y con el estudio de las relaciones que unían a los ministros que más presencia han tenido en los actos analizados, así como los que han poseído una posición principal dentro de las mesas presidenciales con el Jefe del Estado, pretendemos respaldar la hipótesis de que no se sigue un ordenamiento legal en la ubicación de las autoridades en los actos que hemos analizado, sino que por el contrario, en muchas ocasiones, aunque no podemos afirmar que en todas, se sigue un orden parcial, el cual, basándonos en las relaciones que unían a los ministros y al Jefe del Estado, puede atender a los intereses propios de este último. Incluso podemos apuntar que, además de situarse a ciertos ministros en unos puestos con más relevancia, los que más acuden a los actos analizados corresponden con los que mejores relaciones mantienen con el Jefe del Estado o con los consejeros directos de este: Carrero Blanco o Arias Navarro.

Por otro lado, queremos resaltar que la presencia de los ministros en la celebración de estos días señalados en el calendario oficial del régimen franquista, así como la posición privilegiada de muchos de ellos puede llevar a interpretarse con un doble fin. Por un lado, mostrar deferencia con aquellos que colaboran con la causa del Régimen y por otro, contribuir con los presentes en los actos a que, al estar más visibles públicamente, se perciban como los que poseen los cargos más importantes o influyentes dentro de la formación gubernamental, reforzando y fortaleciendo este hecho el poder que ya ostentaban. A esto hay que añadirle que algunos de los ministros que aparecen en los actos habían poseído o poseían varios cargos gubernamentales, lo cual refleja la magnitud del poder que llegaron a ostentar. 


\section{REFERENCIAS}

ALIA MIRANDA, F., DEL VALLE CALZADO, A. R. Y MORALES ENCINAS, O. M. (Coords.), "La Guerra Civil en Castilla-La Mancha, 70 años después", en Actas del Congreso Internacional, Cuenca, Universidad de Castilla La Mancha, 2008.

ÁLVAREZ LÁZARO, P. (Dir.),Cien años de educación en España. En torno a la creación del Ministerio de Instrucción Pública y Bellas Artes. Ministerio de Educación, Cultura y Deporte, 2001.

ARENAL, C. del, Política Exterior de España Hacia Iberoamérica. Madrid, Editorial Complutense, 1994.

BENNASSAR, B., Franco. Madrid, Edaf, 1996.

FERNÁNDEZ-LONGORIA, M., "La Diplomacia Británica y La Caída De Serrano Suñer. Espacio, Tiempo y Forma". Serie V, Historia Contemporánea, 16, 2004, pp. 253-268. Recuperado de http://e-spacio.uned.es/revistasuned/index.php/ETFV/article/view/3101

FRANCO SALGADO-ARAÚJO, F., Mis conversaciones privadas con Franco. Barcelona, Planeta, 1976.

GALLEGO, J. A. (Coord.), Historia general de España y América. Tomo 19, vol. 1. La época de Franco. Madrid, Rialp, 1987.

GIL, V. , Cuarenta años junto a Franco. Barcelona, Planeta, 1981.

LAZO DÍAZ, A., Una Familia Mal Avenida: Falange, Iglesia y Ejército. Madrid, Síntesis, 2008.

MUNIESA I BRITO, B., Dictadura y Transición: La España lampedusiana. I, La dictadura franquista, 1939-1975. Barcelona, Universitat de Barcelona, 2005.

MUÑOZ SORO, J., "Joaquín Ruiz-Giménez o el católico total: apuntes para una biografía política e intelectual hasta 1963". Pasado y Memoria: Revista De Historia Contemporánea, 5,2006, pp. 259-288. Recuperado de http://rua.ua.es/dspace/bitstream/10045/5927/1/PYM_05_13.pdf?origin=publication_detai

PARDO SANZ, R. M., "Fernando María Castiella: pasión política y vocación diplomática". Historia Contemporánea, 15, 1996, pp. 225-240. Recuperado de http://www.historiacontemporanea.ehu.es/s0021con/eu/contenidos/boletin_revista /00021_revista_hc15/es_revista/adjuntos/15_15.pdf

PRESTON, P., Franco: Caudillo de España. Barcelona, DeBolsillo, 2011.

PRESTON, P., Juan Carlos. Rey de un pueblo. Barcelona, Debate, 2012. 
ROMERO, E., ARCO, M. del Y MIGUEL, A. de, Los 90 ministros de Franco. Barcelona, Dopesa, 1971.

SINOVA, J., La censura de prensa durante el franquismo (1936-1951). Barcelona, Debolsillo, 2006.

TOGORES, L. E., Muñoz Grandes: Héroe de Marruecos, General de la División Azul. Madrid, La Esfera de los Libros, 2007.

TOWNSON, N. (Ed.) España en cambio. El segundo franquismo, 1959-1975. Madrid, Siglo XXI de España Editores, 2009.

TUSELL, J., Franco y los católicos. Madrid: Alianza, 1984.

TUSELL, J., Carrero: la eminencia gris del régimen de Franco. Madrid, Ediciones Temas de Hoy, 1993.

VÁZQUEZ, A., Tomás Alvira: Una pasión por la familia. Un maestro de la educación. Madrid, Palabra, 1999.

ZAFRILLA TOBARRA, R., Universidades laborales: un proyecto educativo falangista para el mundo obrero (1955-1978). Aproximación histórica. (Tesis doctoral). Universidad de Castilla La Mancha, Cuenca, 1998 